\title{
Bladder preservation therapy in combination with atezolizumab and radiation therapy for invasive bladder cancer (BPT-ART) - A study protocol for an open-label, phase II, multicenter study
} \author{
Hideyuki Sakurai a , Hiroyuki Nishiyama ${ }^{\text {b, }}$ \\ a Department of Radiation Oncology, Faculty of Medicine, University of Tsukuba, Japan \\ ${ }^{\mathrm{b}}$ Department of Urology, Faculty of Medicine, University of Tsukuba, Japan \\ ${ }^{\mathrm{c}}$ Department of Biostatistics, Faculty of Medicine, University of Tsukuba, Japan \\ ${ }^{\mathrm{d}}$ Department of Urology, Osaka Medical College, Japan \\ e Department of Radiation Oncology, Osaka Medical College, Japan \\ ${ }^{\mathrm{f}}$ Department of Urology, Saitama Cancer Center, Japan \\ ${ }^{g}$ Department of Radiation Oncology, Saitama Cancer Center, Japan \\ ${ }^{\mathrm{h}}$ Department of Diagnostic Pathology, Aichi Medical University Hospital, Japan
}

Yuta Sekino $^{\text {a }}$, Hitoshi Ishikawa ${ }^{a}$, Tomokazu Kimura ${ }^{\mathrm{b}}$, Takahiro Kojima ${ }^{\mathrm{b}}$, Kazushi Maruo ${ }^{\mathrm{c}}$, Haruhito Azuma $^{d}$, Ken Yoshida ${ }^{\mathrm{e}}$, Yukio Kageyama ${ }^{\mathrm{f}}$, Hiroki Ushijima ${ }^{\mathrm{g}}$, Toyonori Tsuzuki ${ }^{\mathrm{h}}$,

\section{A R T I C L E I N F O}

\section{Keywords:}

Bladder preservation therapy

Atezolizumab

Radiation therapy

Immune checkpoint inhibitor

Invasive bladder cancer

Study protocol

\begin{abstract}
A B S T R A C T
Radical cystectomy (RC) is recommended for muscle-invasive bladder cancer (MIBC) or highest-risk non-muscleinvasive bladder cancer (NMIBC). Trimodal therapy (TMT) is the most favorable strategy among bladder preservation therapies (BPT) for patients who are ineligible for or refuse RC. However, referrals for TMT, especially following chemotherapy, are limited by the patient's condition. Therefore, new BPT approaches are needed. Atezolizumab inhibits programmed death-ligand 1, is well-tolerated in patient populations heavily dominated by renal insufficiency, and is expected to have synergistic anti-tumor effects in combination with radiation therapy (RT). Therefore, we have conducted this open-label phase II multicenter study to evaluate the efficacy and safety of RT in combination with atezolizumab for T2-3 MIBC and highest-risk T1 NMIBC patients. This study was initiated in January 2019, and we aimed to enroll a total of 45 patients. The study is registered in the Japan Registry of Clinical Trials (Identifier: RCT2031180060).
\end{abstract}

\section{Background}

Bladder cancer is the 14th most common cancer in Asia and is considered to be a disease of the elderly, with a high incidence in individuals aged over 60 years $[1,2]$. Non-metastatic bladder cancer is classified into non-muscle invasive cancer and muscle invasive cancer, which accounts for about $20-25 \%$ of cases [3,4]. Radical cystectomy (RC) is the primary treatment modality for muscle-invasive bladder cancer (MIBC). While highest-risk non-muscle-invasive bladder cancer (NMIBC) is defined as T1 Grade 3 (G3)/high grade (HG) and is associated with concurrent bladder carcinoma in situ (CIS), multiple, large, and/or recurrent T1G3/HG according to European Association of Urol- ogy guidelines, RC is only indicated for those patients with the highestrisk NMIBC before they progress to muscle-invasive tumor $[5,6]$.

In patients with high-risk NMIBC, intravesical bacillus CalmetteGuérin (BCG) after transurethral resection of the bladder tumor (TURBT) reduces the risk of tumor recurrence [7]. In contrast, RC is also recommended for patients who had been unsuccessfully treated with BCG either due to tumor failure or due to severe side effects, preventing the completion of BCG treatment. Some studies on this have reported positive results [8-12].

However, RC with urinary diversion is very likely to decrease patients' post-treatment comfort and quality of life (QOL). In addition, due to advanced age and comorbidities, some patients are considered unsuitable for cystectomy [13]. Thus, several bladder preservation

\footnotetext{
* Corresponding author. Department of Urology, Faculty of Medicine, University of Tsukuba, 1-1-1 Tennodai, Tsukuba City, Ibaraki 305-8575, Japan. Tel.: + 81 29 853 3223; fax: + 812988538854 .

E-mail address: nishiuro@md.tsukuba.ac.jp (H. Nishiyama).
}

https://doi.org/10.1016/j.conctc.2021.100724

Received 7 May 2020; Received in revised form 9 October 2020; Accepted 11 January 2021

Available online 21 January 2021

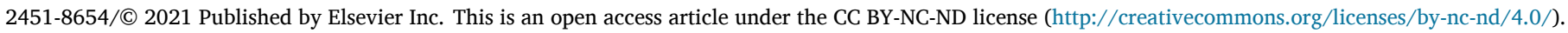


therapies (BPT) have evolved over the past 20 years, utilizing chemotherapy and radiation therapy (RT).

Currently, the most favorable strategy among BPTs is the trimodal therapy (TMT), which consists of transurethral resection of the bladder tumor and concurrent chemoradiation (CCRT). TMT has shown results similar to that of RC, with the advantage of preserving organ function and QOL in selected patients. Table 1 summarizes the clinical results of TMT for MIBC showing that the 5-year overall survival (OS) rates range between 48 and 57\% [14-21] (Table 1).

However, proper patient selection is considered essential for the application of TMT. Some conditions such as tumor invading outside the bladder (cT4), TURBT incompletion, presence of hydronephrosis, presence of CIS, and presence of diffuse multifocal disease are considered to be associated with worse prognosis in patients treated with TMT. Hence, these patients would be better suited for treatment with RC [22-24]. RT is an essential treatment modality for BPT, but historically, RT has mainly been used in patients with frailty or multiple comorbidities that interfere with the use of chemotherapy. Thus, the results of RT alone as BPT are known to be inferior to that of CCRT [25,26]. The 5year overall survival (OS) rates reported by some studies on RT alone range between $24 \%$ and $45 \%$ [27-30].

Chemotherapy used concurrently with RT is aimed as a radiosensitizer in TMT. According to the National Comprehensive Cancer Net-

Table 1

Outcome of trimodal bladder preservation therapy for MIBC.

\begin{tabular}{|c|c|c|c|c|c|c|c|}
\hline Author & Year & Number & $\begin{array}{l}\text { Clinical } \\
\text { stage }\end{array}$ & $\begin{array}{l}3-y \\
\text { OS } \\
(\%)\end{array}$ & $\begin{array}{l}5-y \\
\text { OS } \\
(\%)\end{array}$ & $\begin{array}{l}3-y \\
\text { PFS/DFS } \\
(\%)\end{array}$ & $\begin{array}{l}5-y \\
\text { PFS/DFS } \\
(\%)\end{array}$ \\
\hline $\begin{array}{l}\text { Housset et al. } \\
\text { [14] }\end{array}$ & 1993 & 54 & $\begin{array}{l}\mathrm{T} 2- \\
4 \mathrm{~N}+\end{array}$ & 59 & & 62 & \\
\hline $\begin{array}{l}\text { Hussain et al. } \\
\text { [15] }\end{array}$ & 2004 & 41 & $\begin{array}{l}\mathrm{T} 2- \\
4 \mathrm{~N}+\end{array}$ & & 36 & 65 & $59-67$ \\
\hline $\begin{array}{l}\text { Eapen et al. } \\
\text { [16] }\end{array}$ & 2004 & 185 & $\begin{array}{l}\mathrm{T} 2- \\
4 \mathrm{~N}+\end{array}$ & 60 & 48 & & \\
\hline $\begin{array}{l}\text { Krause et al. } \\
{[17]}\end{array}$ & 2011 & 331 & $\begin{array}{l}\mathrm{T} 2- \\
4 \mathrm{~N}+\end{array}$ & & 54 & & \\
\hline $\begin{array}{l}\text { James et al. } \\
{[18]}\end{array}$ & 2012 & 182 & T2-4 N- & & 48 & & \\
\hline $\begin{array}{l}\text { Tunio et al. } \\
\text { [19] }\end{array}$ & 2012 & 230 & T2-4 N- & 80 & 53 & 80 & 47 \\
\hline $\begin{array}{l}\text { Efstathiou et } \\
\text { al. [20] }\end{array}$ & 2012 & 343 & T2-4 N- & 65 & 52 & & \\
\hline $\begin{array}{l}\text { Mak et al. } \\
\text { [21] }\end{array}$ & 2014 & 468 & T2-4 N- & & 57 & & \\
\hline
\end{tabular}

Abbreviations; MIBC: muscle-invasive bladder cancer, Y: year, OS: overall survival, PFS: rogression free survival, DFS: disease free survival. work (NCCN) guidelines, preferred chemotherapy regimens for organpreserving CCRT are cisplatin alone, 5-FU with or without mitomycin, or paclitaxel when feasible [31].

In contrast, the population of patients with an ideal indication for TMT is limited due to the oncological conditions mentioned above, as well as patient conditions, including advanced age and comorbidities ineligible for chemotherapy. Therefore, new BPT approaches for patients who are unsuitable for CCRT are needed.

The abscopal effect, which induces tumor regression at nonirradiated distant tumor sites, is increasingly recognized in preclinical and clinical studies for the immune-mediated anti-tumor impact of RT $[32,33]$. With the development of immuno-oncology, the synergistic anti-tumor effect of cancer immunotherapy, and especially of immune checkpoint inhibitors, is expected when these agents are combined with RT [34]. Although there is strong evidence from preclinical works that $\mathrm{RT}$ and immunotherapy fit together, clinical reports detailing the interaction of RT with immunotherapies are limited [35-37].

Atezolizumab is a monoclonal antibody that suppresses programmed death-ligand 1 (PD-L1). Studies have shown its efficacy and acceptable safety profile in various cancers, including metastatic urothelial carcinoma. Even in patients with renal insufficiency, atezolizumab appears to be safe and well-tolerated [38-40].

To our knowledge, several small single-arm phase I/II trials and one phase III trial have been conducted, where PD-1 or PD-L1 inhibitors were used as neoadjuvant or adjuvant therapy in combination with RT or CCRT (Table 2). Therefore, we have planned this open-label phase II multicenter study (BPT-ART) to evaluate the efficacy and safety of RT combined with atezolizumab for clinical T2-3 MIBC and highest-risk T1 NMIBC patients who were considered unsuitable for RC or refused RC. We will also assess the efficacy and safety of long-term administration of atezolizumab in this setting.

\section{Materials and methods}

\subsection{Study design}

Participating sites are the following: University of Tsukuba, Osaka Medical College, and Saitama Cancer Center in Japan. This trial is registered in the Japan Registry of Clinical Trials (Identifier: RCT2031180060), and the study protocol was approved by the independent ethics committee of each study site. The inclusion and exclusion criteria are listed in Table 3. The patients who were suitable for concurrent chemoradiotherapy were not excluded.

Table 2

Ongoing trials of immune checkpoint inhibitors for non-metastatic bladder cancer.

\begin{tabular}{|c|c|c|c|c|c|c|}
\hline Drug & Trial & Population & Radiation therapy & Combined drugs & Number & Primary endpoint \\
\hline Pembrolizumab & NCT02662062 & T2-4aNxM0 & $64 \mathrm{~Gy} / 32 \mathrm{Fr}$ & Cisplatin & 30 & MTD \\
\hline Pembrolizumab & NCT02621151 & T2-4aNOM0 unsuitable or refused RC & $52 \mathrm{~Gy} / 26 \mathrm{Fr}$ & Gemcitabine & 54 & 2y-BIDFS \\
\hline $\begin{array}{c}\text { Pembrolizumab } \\
>\text { Withdraw }\end{array}$ & NCT02560636 & $\mathrm{T} 2-4 \mathrm{NxMx}$ & $36 \mathrm{~Gy} / 6 \mathrm{Fr} / 6$ weeks & - & 34 & MTD \\
\hline Durvalumab & NCT03150836 & T3-4NxMx & $33 \mathrm{~Gy} / 5 \mathrm{Fr}$ & - & 6 & Toxicity \\
\hline $\begin{array}{l}\text { Durvalumab } \\
\quad+\text { Tremelimumab }\end{array}$ & NCT03702179 & T2-4aNOMO & $\begin{array}{l}46 \text { Gy (small pelvis) } \\
18-20 \text { Gy (bladder) }\end{array}$ & - & 32 & Pathological response \\
\hline Avelumab & NCT03747419 & T2-4aN0M0 & Undescribed (2 way) & - & 24 & 3y-Complete CCR \\
\hline Avelumab & NCT03950362 & $\begin{array}{l}\text { T1N0M0 } \\
\text { BCG unresponsive }\end{array}$ & 60-66 Gy (bladder) & - & 67 & 1y-High risk RFS (HG,T1,CIS) \\
\hline $\begin{array}{l}\text { Ipilimumab } \\
+ \text { Nivolumab }\end{array}$ & NCT03844256 & T2-4aN0-1M0 & $40 \mathrm{~Gy} / 20 \mathrm{Fr}$ & MMC, capecitabine & 50 & $\begin{array}{l}\text { Toxicity, DLT, } \\
\text { 5y-DFS, 5y-DFS rate }\end{array}$ \\
\hline Atezolizumab & NCT03620435 & T2-4aNOM0 & $50 \mathrm{~Gy} / 25 \mathrm{Fr}$ & Gemcitabine & 25 & Toxicity \\
\hline Atezolizumab & NCT03697850 & T2-3N0MO & $>60 \mathrm{~Gy}$ & Any & 77 & DFS \\
\hline Atezolizumab & NCT03775265 & T2-4aNOMO & Undescribed & $\begin{array}{l}\text { GEM, CDDP, } \\
\text { 5-FU, MMC }\end{array}$ & 475 & 5y-BI-EFS \\
\hline
\end{tabular}

Abbreviations; y: year, BIDFS: bladder-intact disease-free survival rate, MTD: maximum tolerated dose, CCR: clinical response rate, RFS: relapse free survival, BI-EFS: bladder intact event-free survival, DLT: incidence of dose limiting toxicity, DFS: disease free survival. 
Table 3

Inclusion and exclusion criteria.

\begin{tabular}{|c|c|}
\hline Inclusion criteria & Exclusion criteria \\
\hline $\begin{array}{l}\text { - Age }>20 \text { years } \\
\text { - Patients who underwent transurethral } \\
\text { bladder tumor resection (TURBT) within } \\
90 \text { days prior to enrollment and have been } \\
\text { histologically diagnosed with urothelial } \\
\text { cancer } \\
\text { - cT1-3NOM0 invasive bladder cancer } \\
\text { (UICC/AJCC 8th edition) Patients who are } \\
\text { unsuitable for radical cystectomy or } \\
\text { refused radical cystectomy } \\
\text { - For patients with cT1N0M0, at least one } \\
\text { of the following (highest risk group T1) } \\
\text { a) Multiple T1 tumors (more than } 2 \text { ) } \\
\text { b) Remaining T1 lesion on the tissue of } 2 \text { nd- } \\
\text { TUR } \\
\text { c) T1 tumor with associated CIS } \\
\text { d) BCG resistant T1 tumor } \\
\text { e) Recurrent T1 tumor with BCG } \\
\text { intolerance } \\
\text { - For patients with cT2-3N0M0, maximum } \\
\text { tumor diameter is } 5 \text { cm or less } \\
\text { - Patients with } 0 \text { or } 1 \text { Performance Status } \\
\text { (PS) (Eastern Cooperative Oncology } \\
\text { Group: ECOG) }\end{array}$ & $\begin{array}{l}\text { Patients with extension to the } \\
\text { prostate (cT4), upper urinary } \\
\text { tract tumor, and urethral tumor. } \\
\text { Patients with hydronephrosis } \\
\text { Patients with previous } \\
\text { autoimmune disease or those } \\
\text { who had received therapies } \\
\text { targeting CD137, CTLA4, or PD- } \\
\text { L1-PD-1, } \\
\text { Other malignancy within the } \\
\text { past } 5 \text { year }\end{array}$ \\
\hline
\end{tabular}

\subsection{Endpoints}

The primary endpoint is progression-free survival (PFS). The primary evaluation analysis is planned to be performed after a 3-year follow-up for all patients. The major secondary endpoint is pathological complete remission (pCR) rates 24 weeks after atezolizumab administration. The pCR rate will be analyzed during the pCR assessment for all patients by the central pathology review. The presence or absence of a complete pathological response is known to affect recurrence and prognosis after chemoradiation for bladder cancer [21]. Other secondary endpoints are recurrence-free-survival (RFS), overall survival (OS), bladder-preservation rate (BPR), and duration of complete remission (CR). Safety is also assessed according to the Common Terminology Criteria for Adverse Events (CTCAE) v4.0 [41].

\subsection{Statistical analyses}

Primary analysis is using the Kaplan-Meier method to estimate PFS at three years and its 95\% confidence interval based on the double logtransformation. We will judge the efficacy when the lower confidence limit exceeds $45 \%$. Secondary analyses are using the Kaplan-Meier method to estimate PFS at one and two years and calculating PCR rate at 24 weeks.

\subsection{Sample-size calculation}

Based on previously published data, the 3-year OS rate after RC was $64 \%-70 \%$ for stage II, $44 \%-54 \%$ for stage III, and the 3 -year PFS rate was $52 \%-78 \%$ [42-44]. In cases of TMT for MIBC, the 3-year OS and PFS rates were $60 \%-80 \%$ and $62 \%-80 \%$, respectively [14-21]. We therefore hypothesized that, in this study, we expect a 3-year PFS of $70 \%$, and the threshold is set at $45 \%$. Threshold was determined based on the previous results of radiotherapy alone. We determined that the 3 -year PFS could be approximated by a 5-year OS because there were no reports of a 3-year PFS with radiotherapy alone, and the median survival of recurrent metastatic urothelial carcinoma is approximately 2 years [45]. With a 5 -year OS of $24-40 \%$ for radiotherapy alone
[27-30], we set the threshold at $45 \%$. A total of 34 patients will yield an $80 \%$ success probability for the primary analysis $(95 \%$ lower confidence limit exceeds $45 \%$ ). To compensate for ineligible patients and lost follow-up mainly due to an elderly population, the target number of patients is set at 45 .

\subsection{Protocol treatment}

Patients will first receive RT combined with intravenous atezolizumab ( $1200 \mathrm{mg} /$ body) administered every 21 days and repeated at 8 cycles. In terms of RT, a total irradiation dose of $41.4 \mathrm{~Gy}$ in 23 daily fractions will be given to the small pelvis and 16.2 Gy in 9 daily fractions to the whole bladder. We selected the small pelvic irradiation because the probability of lymph node metastasis is $10-40 \%$ in stages II-III $[46,47]$ and to be comparable with the past clinical trials to evaluate safety and efficacy [21]. Patients will undergo response assessments using CT imaging and cystoscopy at baseline and every 12 weeks for 12 months thereafter until disease progression, withdrawal of consent, or death, and pathological evaluation by a central independent facility is planned using TUR biopsy as an interim evaluation at 24 weeks for tumor control. Patients without recurrence or progression at interim evaluation will continue to receive an additional 7 cycles of atezolizumab every 21 days until unacceptable toxicity or progression of the disease.

\section{Discussion}

RC is the golden standard for highest-risk NMIBC and MIBC, but TMT is considered to be as attractive a method as BPT. Although there is no randomized controlled trial comparing the results of RC with TMT, the evidence suggest that TMT has successfully provided comparable outcomes to RC over the past decades in some populations [48]. In contrast, a large number of patients who are either elderly or have impaired renal function are unable to receive cisplatin-based systemic chemotherapy in actual clinical practice. Hence, the present study is designed to investigate the safety and efficacy of RT combined with atezolizumab, an immune checkpoint inhibitor, for highest-risk clinical T1 NMIBC and T2-3 MIBC patients who are unfit for or refuse RC. The study is not considered to be a randomized trial comparing conventional TMT with utilizing cisplatin due to the nature of the target patients. For these reasons, this study was conducted as an open-label phase II study.

The primary rationale for combining atezolizumab and RT in this patient group is twofold. First, atezolizumab generally seems to be safe and well-tolerated even in patients who are ineligible for systemic chemotherapy such as cisplatin because of their comorbidities [40].

Second, combining RT and immune checkpoint inhibitors is expected to induce a synergistic abscopal effect, which can cause tumor regression at not only the irradiated field but also out of the irradiated field.

For these reasons, the results of this study will provide a new treatment option of BPT for bladder cancer patients who are ineligible for the standard TMT by CCRT using cisplatin-based chemotherapy.

\section{Ethics approval}

The institutional review board of the University of Tsukuba Hospital (Approval \#I-29).

\section{Funding}

This study was partly supported by JSPS KAKENHI Grant Number JP17K10467 and funded by Chugai Pharmaceutical Co Ltd. The funding sponsors had no role in the design of the study and the writing of the manuscript. 


\section{Declaration of competing interest}

Dr. Nishiyama reports personal fees and other support from Chugai Pharmaceutical Co Ltd, during the conduct of the study. Dr. Kimura reports other support from Chugai Pharmaceutical Co Ltd, during the conduct of the study. Dr. Tsuzuki reports honoraria and non-financial support from Chugai, honoraria from AstraZeneca, Nippon Kayaku, Takeda, Janssen, Astellas, Pfizer, Novartis, Bayer, Ono, and Bristol Myers Squibb. The other authors declare that they have no competing interests.

\section{Acknowledgements}

The authors would like to thank Tsukuba Clinical Research and Development Organization (T-CReDO) for medical writing support and advice on regulatory matters and Editage (www.editage.com) for English language editing.

\section{References}

[1] M. Hori, T. Matsuda, A. Shibata, K. Katanoda, T. Sobue, H. Nishimoto, Cancer incidence and incidence rates in Japan in 2009: a study of 32 population-based cancer registries for the Monitoring of Cancer Incidence in Japan (MCIJ) project, Jpn. J. Clin. Oncol. 45 (2015) 884-891, https://doi.org/10.1093/jjco/hyv088.

[2] H. Nishiyama, Asia consensus statement on NCCN clinical practice guideline for bladder cancer, Jpn. J. Clin. Oncol. 48 (2018) 3-6, https://doi.org/10.1093/jjco/ hyx130.

[3] A.B. Smith, A.M. Deal, M.E. Woods, E.M. Wallen, R.S. Pruthi, R.C. Chen, M.I. Milowsky, M.E. Nielsen, Muscle-invasive bladder cancer: evaluating treatment and survival in the national cancer data base, BJU Int. 114 (2014) 719-726, https://doi. org/10.1111/bju.12601.

[4] A. El-Achkar, L. Souhami, W. Kassouf, Bladder preservation therapy: review of literature and future directions of trimodal therapy, Curr. Urol. Rep. 19 (2018), https://doi.org/10.1007/s11934-018-0859-z.

[5] B.P. Schrier, M.P. Hollander, B.W.G. Van Rhijn, L.A.L.M. Kiemeney, J.A. Witjes, Prognosis of muscle-invasive bladder cancer: difference between primary and progressive tumours and implications for therapy, Eur. Urol. 45 (2004) 292-296, https://doi.org/10.1016/j.eururo.2003.10.006.

[6] M. Moschini, V. Sharma, P. Dell'Oglio, V. Cucchiara, G. Gandaglia, F. Cantiello, F. Zattoni, F. Pellucchi, A. Briganti, R. Damiano, F. Montorsi, A. Salonia, R. Colombo, Comparing long-term outcomes of primary and progressive carcinoma invading bladder muscle after radical cystectomy, BJU Int. 117 (2016) 604-610, https://doi. org/10.1111/bju.13146.

[7] P.U. Malmström, R.J. Sylvester, D.E. Crawford, M. Friedrich, S. Krege, E. Rintala, E. Solsona, S.M. Di Stasi, J.A. Witjes, An individual patient data meta-analysis of the long-term outcome of randomised studies comparing intravesical mitomycin C versus Bacillus calmette-guérin for non-muscle-invasive bladder cancer, Eur. Urol. 56 (2009) 247-256, https://doi.org/10.1016/j.eururo.2009.04.038.

[8] J.T. Ark, K.A. Keegan, D.A. Barocas, T.M. Morgan, M.J. Resnick, C. You, M.S. Cookson, D.F. Penson, R. Davis, P.E. Clark, J.A. Smith, S.S. Chang, Incidence and predictors of understaging in patients with clinical T1 urothelial carcinoma undergoing radical cystectomy, BJU Int. 113 (2014) 894-899, https://doi.org/10. 1111/bju.12245.

[9] H.M. Fritsche, M. Burger, R.S. Svatek, C. Jeldres, P.I. Karakiewicz, G. Novara, E. Skinner, S. Denzinger, Y. Fradet, H. Isbarn, P.J. Bastian, B.G. Volkmer, F. Montorsi, W. Kassouf, D. Tilki, W. Otto, U. Capitanio, J.I. Izawa, V. Ficarra, S. Lerner, A.I. Sagalowsky, M. Schoenberg, A. Kamat, C.P. Dinney, Y. Lotan, S.F. Shariat, Characteristics and outcomes of patients with clinical T1 Grade 3 urothelial carcinoma treated with radical cystectomy: results from an international cohort, Eur. Urol. 57 (2010) 300-309, https://doi.org/10.1016/j.eururo.2009.09.024.

[10] G.N. Thalmann, R. Markwalder, O. Shahin, F.C. Burkhard, W.W. Hochreiter, U.E. Studer, Primary T1G3 bladder cancer: organ preserving approach or immediate cystectomy?, J. Urol. 172 (2004) 70-75, https://doi.org/10.1097/01.ju. 0000132129.87598.3b.

[11] S. Denzinger, H.M. Fritsche, W. Otto, A. Blana, W.F. Wieland, M. Burger, Early versus deferred cystectomy for initial high-risk pT1G3 urothelial carcinoma of the bladder: do risk factors define feasibility of bladder-sparing approach?, Eur. Urol. 53 (2008) 146-152, https://doi.org/10.1016/j.eururo.2007.06.030.

[12] A.S. Solsona E, I. Iborra, R. Dumont, J. Rubio-Briones, J. Casanova, The 3-month clinical response to intravesical therapy as a predictive factor for progression in patients with high risk superficial bladder cancer, J. Urol. 164 (2000) 685-689, https://doi.org/10.1097/00005392-200009010-00016.

[13] K.S. Mak, A.B. Smith, A. Eidelman, R. Clayman, A. Niemierko, J.S. Cheng, J. Matthews, M.R. Drumm, M.E. Nielsen, A.S. Feldman, R.J. Lee, A.L. Zietman, R.C. Chen, W.U. Shipley, M.I. Milowsky, J.A. Efstathiou, Quality of life in long-term survivors of muscle-invasive bladder cancer, Int. J. Radiat. Oncol. Biol. Phys. 96 (2016) 1028-1036, https://doi.org/10.1016/j.ijrobp.2016.08.023.

[14] M. Housset, C. Maulard, Y. Chretien, B. Dufour, S. Delanian, J. Huart, F. Colardelle, P. Brunel, F. Baillet, Combined radiation and chemotherapy for invasive transitional-cell carcinoma of the bladder: a prospective study, J. Clin. Oncol. 11
(1993) 2150-2157, https://doi.org/10.1200/JCO.1993.11.11.2150.

[15] S.A. Hussain, D.D. Stocken, D.R. Peake, J.G. Glaholm, A. Zarkar, D.M.A. Wallace, N D. James, Long-term results of a phase II study of synchronous chemoradiotherapy in advanced muscle invasive bladder cancer, Br. J. Canc. 90 (2004) 2106-2111, https://doi.org/10.1038/sj.bjc.6601852.

[16] L. Eapen, D. Stewart, J. Collins, R. Peterson, Effective bladder sparing therapy with intra-arterial cisplatin and radiotherapy for localized bladder cancer, J. Urol. 172 (2004) 1276-1280, https://doi.org/10.1097/01.ju.0000140456.42509.b6.

[17] F.S. Krause, B. Walter, O.J. Ott, L. Häberle, C. Weiss, C. Rödel, B. Wullich, R. Sauer, 15-Year survival rates after transurethral resection and radiochemotherapy or radiation in bladder cancer treatment, Anticancer Res. 31 (2011) 985-990 http:// www.ncbi.nlm.nih.gov/pubmed/21498726.

[18] N.D. James, S.A. Hussain, E. Hall, P. Jenkins, J. Tremlett, C. Rawlings, M. Crundwell, B. Sizer, T. Sreenivasan, C. Hendron, R. Lewis, R. Waters, R.A. Huddart, Radiotherapy with or without chemotherapy in muscle-invasive bladder cancer, N. Engl. J. Med. 366 (2012) 1477-1488, https://doi.org/10.1056/NEJMoa1106106.

[19] M.A. Tunio, A. Hashmi, A. Qayyum, R. Mohsin, A. Zaeem, Whole-pelvis or bladderonly chemoradiation for lymph node-negative invasive bladder cancer: singleinstitution experience, Int. J. Radiat. Oncol. Biol. Phys. 82 (2012) e457-e462, https://doi.org/10.1016/j.ijrobp.2011.05.051.

[20] J.A. Efstathiou, D.Y. Spiegel, W.U. Shipley, N.M. Heney, D.S. Kaufman, A. Niemierko, J.J. Coen, R.Y. Skowronski, J.J. Paly, F.J. McGovern, A.L. Zietman, Long-term outcomes of selective bladder preservation by combined-modality therapy for invasive bladder cancer: the MGH experience, Eur. Urol. 61 (2012) 705-711, https://doi.org/10.1016/j.eururo.2011.11.010.

[21] R.H. Mak, D. Hunt, W.U. Shipley, J.A. Efstathiou, W.J. Tester, M.P. Hagan, D.S. Kaufman, N.M. Heney, A.L. Zietman, Long-term outcomes in patients with muscleinvasive bladder cancer after selective bladder-preserving combined-modality therapy: a pooled analysis of radiation therapy oncology group protocols 8802 , 8903, 9506, 9706, 9906, and 0233, J. Clin. Oncol. 32 (2014) 3801-3809, https:// doi.org/10.1200/JCO.2014.57.5548.

[22] G. Gakis, J.A. Witjes, E. Compérat, N.C. Cowan, M. De Santis, T. Lebret, M.J. Ribal, A.M. Sherif, EAU guidelines on primary urethral carcinoma, Eur. Urol. 64 (2013) 823-830, https://doi.org/10.1016/j.eururo.2013.03.044.

[23] N.J. Giacalone, W.U. Shipley, R.H. Clayman, A. Niemierko, M. Drumm, N.M. Heney, M.D. Michaelson, R.J. Lee, P.J. Saylor, M.F. Wszolek, A.S. Feldman, D.M. Dahl, A.L. Zietman, J.A. Efstathiou, Long-term outcomes after bladder-preserving tri-modality therapy for patients with muscle-invasive bladder cancer: an updated analysis of the Massachusetts general hospital experience, Eur. Urol. 71 (2017) 952-960, https:// doi.org/10.1016/j.eururo.2016.12.020.

[24] E. ichiro Takaoka, J. Miyazaki, H. Ishikawa, K. Kawai, T. Kimura, R. Ishitsuka, T. Kojima, R. Kanuma, D. Takizawa, T. Okumura, H. Sakurai, H. Nishiyama, Long-term single-institute experience with trimodal bladder-preserving therapy with proton beam therapy for muscle-invasive bladder cancer, Jpn. J. Clin. Oncol. 47 (2017) 67-73, https://doi.org/10.1093/jjco/hyw151.

[25] D.B. Cahn, E.A. Handorf, E.M. Ghiraldi, B.T. Ristau, D.M. Geynisman, T.M. Churilla, E.M. Horwitz, M.L. Sobczak, D.Y.T. Chen, R. Viterbo, R.E. Greenberg, A. Kutikov, R. G. Uzzo, M.C. Smaldone, Contemporary use trends and survival outcomes in patients undergoing radical cystectomy or bladder-preservation therapy for muscleinvasive bladder cancer, Cancer 123 (2017) 4337-4345, https://doi.org/10.1002/ cncr.30900.

[26] B.W. Fischer-Valuck, Y.J. Rao, S. Rudra, D. Przybysz, E. Germino, P. Samson, B.C. Baumann, H. Gay, J. Michalski, Treatment patterns and overall survival outcomes of octogenarians with muscle invasive cancer of the bladder: an analysis of the national cancer database, J. Urol. 199 (2018) 416-423, https://doi.org/10.1016/j. juro.2017.08.086

[27] S. Borgaonkar, A. Jain, P. Bollina, D.B. Mclaren, D. Tulloch, G.R. Kerr, G.C.W. Howard, Radical radiotherapy and salvage cystectomy as the primary management of transitional cell carcinoma of the bladder. Results following the introduction of a CT planning technique, Clin. Oncol. 14 (2002) 141-147, https://doi.org/10.1053/ clon.2002.0055.

[28] S.D. Fosså, H. Wæhre, N. Aass, A.B. Jacobsen, D.R. Olsen, S. Ous, Bladder cancer definitive radiation therapy of muscle-invasive bladder cancer: a retrospective analysis of 317 patients, Cancer 72 (1993) 3036-3043, https://doi.org/10.1002/ 1097-0142(19931115)72:10<3036::AID-CNCR2820721028 > 3.0.CO;2-B.

[29] M.K. Gospodarowicz, W.D. Rider, C.W. Keen, J.G. Connolly, M.A.S. Jewett, B.J. Cummings, W. Duncan, P. Warde, T. Chua, Bladder cancer: long-term follow-up results of patients treated with radical radiation, Clin. Oncol. 3 (1991) 155-161, https://doi.org/10.1016/S0936-6555(05)80838-6.

[30] A. Pollack, G.K. Zagars, D.A. Swanson, Muscle-invasive bladder cancer treated with external beam radiotherapy: prognostic factors, Int. J. Radiat. Oncol. Biol. Phys. 30 (1994) 267-277, https://doi.org/10.1016/0360-3016(94)90004-3.

[31] National Comprehensive Cancer Network, Bladder cancer version 4.2019 2019. https://www.nccn.org/professionals/physician_gls/pdf/bladder.pdf. (Accessed 1 August 2019).

[32] N. Shaverdian, A.E. Lisberg, K. Bornazyan, D. Veruttipong, J.W. Goldman, S.C. Formenti, E.B. Garon, P. Lee, Previous radiotherapy and the clinical activity and toxicity of pembrolizumab in the treatment of non-small-cell lung cancer: a secondary analysis of the KEYNOTE-001 phase 1 trial, Lancet Oncol. 18 (2017) 895-903, https://doi.org/10.1016/S1470-2045(17)30380-7.

[33] R.H. Mole, Whole body irradiation; radiobiology or medicine?, Br. J. Radiol. 26 (1953) 234-241, https://doi.org/10.1259/0007-1285-26-305-234.

[34] Y. Liu, Y. Dong, L. Kong, F. Shi, H. Zhu, J. Yu, Abscopal effect of radiotherapy combined with immune checkpoint inhibitors, J. Hematol. Oncol. 11 (2018) 1-15, https://doi.org/10.1186/s13045-018-0647-8.

[35] M.A. Postow, M.K. Callahan, C.A. Barker, Y. Yamada, J. Yuan, S. Kitano, Z. Mu, T. 
Rasalan, M. Adamow, E. Ritter, C. Sedrak, A.A. Jungbluth, R. Chua, A.S. Yang, R.A. Roman, S. Rosner, B. Benson, J.P. Allison, A.M. Lesokhin, S. Gnjatic, J.D. Wolchok, Immunologic correlates of the abscopal effect in a patient with melanoma, N. Engl. J. Med. 366 (2012) 925-931, https://doi.org/10.1056/NEJMoa1112824.

[36] S.M. Hiniker, D.S. Chen, S. Reddy, D.T. Chang, J.C. Jones, J.A. Mollick, S.M. Swetter, S.J. Knox, A Systemic complete response of metastatic melanoma to local radiation and immunotherapy, Transl. Oncol. 5 (2012) 404-407, https://doi.org/ 10.1593/tlo.12280.

[37] A. Derer, B. Frey, R. Fietkau, U.S. Gaipl, Immune-modulating properties of ionizing radiation: rationale for the treatment of cancer by combination radiotherapy and immune checkpoint inhibitors, Cancer Immunol, Immunotherapy 65 (2016) 779-786, https://doi.org/10.1007/s00262-015-1771-8.

[38] D.S. Chen, I. Mellman, Oncology meets immunology: the cancer-immunity cycle, Immunity 39 (2013) 1-10, https://doi.org/10.1016/j.immuni.2013.07.012.

[39] R.S. Herbst, J.C. Soria, M. Kowanetz, G.D. Fine, O. Hamid, M.S. Gordon, J.A Sosman, D.F. McDermott, J.D. Powderly, S.N. Gettinger, H.E.K. Kohrt, L. Horn, D.P. Lawrence, S. Rost, M. Leabman, Y. Xiao, A. Mokatrin, H. Koeppen, P.S. Hegde, I. Mellman, D.S. Chen, F.S. Hodi, Predictive correlates of response to the anti-PD-L1 antibody MPDL3280A in cancer patients, Nature 515 (2014) 563-567, https://doi. org/10.1038/nature14011.

[40] T. Powles, I. Durán, M.S. van der Heijden, Y. Loriot, N.J. Vogelzang, U. De Giorgi, S. Oudard, M.M. Retz, D. Castellano, A. Bamias, A. Fléchon, G. Gravis, S. Hussain, T. Takano, N. Leng, E.E. Kadel, R. Banchereau, P.S. Hegde, S. Mariathasan, N. Cui, X. Shen, C.L. Derleth, M.C. Green, A. Ravaud, Atezolizumab versus chemotherapy in patients with platinum-treated locally advanced or metastatic urothelial carcinoma (IMvigor211): a multicentre, open-label, phase 3 randomised controlled trial, Lancet 391 (2018) 748-757, https://doi.org/10.1016/S0140-6736(17)33297-X.

[41] U.S.D. of H. and H.S. National Cancer Institute, National Institutes of Health, Common Terminology Criteria for Adverse Events v4.0, NIH Publ, 2009 0-71 http://evs.nci.nih.gov/ftp1/CTCAE/CTCAE_4.03_2010-06-14_QuickReference_ $5 \times 7$.pdf. (Accessed 1 August 2019)
[42] H.B. Grossman, R.B. Natale, C.M. Tangen, V.O. Speights, N.J. Vogelzang, D.L. Trump, R.W. DeVere White, M.F. Sarosdy, D.P. Wood, D. Raghavan, E.D. Crawford, Neoadjuvant chemotherapy plus cystectomy compared with cystectomy alone for locally advanced bladder cancer, N. Engl. J. Med. 349 (2003) 859-866, https://doi. org/10.1056/NEJMoa022148.

[43] S.F. Shariat, P.I. Karakiewicz, G.S. Palapattu, Y. Lotan, C.G. Rogers, G.E. Amiel, A. Vazina, A. Gupta, P.J. Bastian, A.I. Sagalowsky, M.P. Schoenberg, S.P. Lerner, Outcomes of radical cystectomy for transitional cell carcinoma of the bladder: a contemporary series from the bladder cancer Research consortium, J. Urol. 176 (2006) 2414-2422, https://doi.org/10.1016/j.juro.2006.08.004.

[44] R.E. Hautmann, R.C. De Petriconi, C. Pfeiffer, B.G. Volkmer, Radical cystectomy for urothelial carcinoma of the bladder without neoadjuvant or adjuvant therapy: longterm results in 1100 patients, Eur. Urol. 61 (2012) 1039-1047, https://doi.org/10. 1016/j.eururo.2012.02.028.

[45] D.F. Bajorin, P.M. Dodd, M. Mazumdar, M. Fazzari, J.A. McCaffrey, H.I. Scher, H. Herr, G. Higgins, M.G. Boyle, Long-term survival in metastatic transitional-cell carcinoma and prognostic factors predicting outcome of therapy, J. Clin. Oncol. 17 (1999) 3173-3181, https://doi.org/10.1200/JCO.1999.17.10.3173.

[46] H. Nishiyama, T. Habuchi, J. Watanabe, S. Teramukai, H. Tada, Y. Ono, S. Ohshima, K. Fujimoto, Y. Hirao, M. Fukushima, O. Ogawa, Clinical outcome of a large-scale multi-institutional retrospective study for locally advanced bladder cancer: a survey including 1131 patients treated during 1990-2000 in Japan, Eur. Urol. 45 (2004) 176-181, https://doi.org/10.1016/j.eururo.2003.09.011.

[47] J. Leissner, R. Hohenfellner, J.W. Thüroff, H.K. Wolf, Lymphadenectomy in patients with transitional cell carcinoma of the urinary bladder; Significance for staging and prognosis, BJU Int. 85 (2000) 817-823, https://doi.org/10.1046/j.1464-410X. 2000.00614.x.

[48] G. Arcangeli, L. Strigari, S. Arcangeli, Radical cystectomy versus organ-sparing trimodality treatment in muscle-invasive bladder cancer: a systematic review of clinical trials, Crit. Rev. Oncol. Hematol. 95 (2015) 387-396, https://doi.org/10. 1016/j.critrevonc.2015.04.006. 